\title{
Relationship between Cadmium Fractions Obtained by Sequential Extraction of Soil and the Soil Properties in Contaminated and Uncontaminated Paddy Soils
}

\author{
Toshimitsu Honma, ${ }^{1}$ Hirotomo Ohba, ${ }^{1}$ Tomoyuki Makino, ${ }^{2}$ and Takuji Ohyama ${ }^{3}$ \\ ${ }^{1}$ Agro-Environment and Management Research Division, Niigata Agricultural Research Institute, Nagaoka 940-0826, Japan \\ ${ }^{2}$ Soil Environment Division, National Institute for Agro-Environmental Sciences, Tsukuba 305-8604, Japan \\ ${ }^{3}$ Faculty of Agriculture, Department of Applied Biological Chemistry, Niigata University, Niigata, Japan \\ Correspondence should be addressed to Toshimitsu Honma; honnma@ari.pref.niigata.jp
}

Received 6 March 2015; Accepted 6 July 2015

Academic Editor: Yong Sik Ok

Copyright (C) 2015 Toshimitsu Honma et al. This is an open access article distributed under the Creative Commons Attribution License, which permits unrestricted use, distribution, and reproduction in any medium, provided the original work is properly cited.

\begin{abstract}
The method for the sequential extraction of cadmium from soil was adapted to investigate the relationship between different chemical forms of cadmium in soils and the soil properties of Cd-contaminated and uncontaminated paddy soils. Air-dried soil samples from each field site were sequentially fractionated into five forms: exchangeable Cd, inorganically bound Cd, organically bound $\mathrm{Cd}$, oxide-occluded fraction, and residual $\mathrm{Cd}$. The average and range of soil properties such as $\mathrm{pH}$, total $\mathrm{C}$, total $\mathrm{N}$, $\mathrm{CEC}$, exchangeable $\mathrm{Ca}, \mathrm{Mg}, \mathrm{K}$, base saturation, available phosphate, particle size distribution, free iron oxide, oxalate extractable $\mathrm{Al}$, and Fe were somewhat similar between uncontaminated and contaminated soils. The average total Cd in uncontaminated and contaminated soils was 0.26 and $0.65 \mathrm{mg} \mathrm{kg}^{-1}$, respectively. The proportions of soil Cd fractions did not differ between the uncontaminated and contaminated soils, although the Cd concentration of several fractions in contaminated soils was statistically higher than those in uncontaminated soils except for residual fraction. The proportion of exchangeable Cd was correlated with the CEC and phosphate absorption coefficient in contaminated soil but not in uncontaminated soil. Thus, soil properties appear to affect the proportions of soil $\mathrm{Cd}$ fractions in contaminated soil and should be considered when evaluating soil Cd mobility.
\end{abstract}

\section{Introduction}

Under Japan's Food Sanitation Act, the Cd concentration of unpolished rice must not be higher than $0.4 \mathrm{mg} \mathrm{kg}^{-1}$ on or after February 28, 2011 [1]. The official method for extracting soil Cd to estimate the extent of soil contamination generally uses a $0.1 \mathrm{~mol} \mathrm{~L}^{-1} \mathrm{HCl}$ solution, but the concentration of Cd estimated by this method tends to be unrelated to the $\mathrm{Cd}$ concentration of unpolished rice grains [2,3]. Therefore, various extraction methods have been tested to determine the plant-available $\mathrm{Cd}$ concentration in contaminated soil, and the $\mathrm{Cd}$ concentrations in some upland plants have shown high correlations with plant-available soil Cd concentrations $[4,5]$.

Despite this progress, the association of soil properties with the Cd concentration of paddy rice-especially the rice grain-has not been evaluated [2] because the rapid shifts between submerged and drained conditions affect the solubility of soil Cd due to the change in oxidation-reduction potential. Chino [6] reported that most of the Cd taken up by rice plants in the 10 days after heading was transported to the grain but that the final Cd concentration was determined by the oxidation-reduction potential in this period. The $\mathrm{Cd}$ concentration of rice grown in paddy soil was greatly affected by the number of days of dry conditions after heading [7]. It is therefore difficult to estimate the $\mathrm{Cd}$ concentration of rice grains by analyzing dried soil. Nevertheless, an assessment of potential risk apart from the influence of the water condition of soils is useful for zoning high-risk fields and deciding on countermeasures or remediation.

The sequential extraction of soil $\mathrm{Cd}$ can be used to evaluate Cd behavior in soil and its availability to plants. 
The proportion of exchangeable $\mathrm{Cd}(\mathrm{ex}-\mathrm{Cd})$ is much higher in contaminated soil than in uncontaminated soil [8]. Hattori et al. [9] found that it is possible to estimate the Cd concentration of brown rice from the ex-Cd concentration in the soil at the time of heading. This result suggests that the $\mathrm{Cd}$ concentration in rice grains may be affected by the ex-Cd concentration in the soil. However, the ex-Cd concentration decreases with increasing soil pH [10], submergence [11], or the application of organic matter [12]. Correlation analysis also revealed that $\mathrm{pH}$ was the most dominant soil variable affecting soil solution Cd concentration and sorption and desorption of native and added Cd in 29 New Zealand soils. However, organic matter (OM), cation exchange capacity (CEC), and total soil Cd were also found to be important [13]. The exchangeable fraction of $\mathrm{Cd}$ as determined by $1 \mathrm{M} \mathrm{MgCl}_{2}$ in the sequential extraction procedure increased, whereas the $\mathrm{Fe}-\mathrm{Mn}$ oxide bound fraction decreased, with increasing levels of organic matter addition [14]. As mentioned above, some soil properties could influence the solubility and mobility of soils Cd, and the degree of the influence is thought to be different between contaminated and uncontaminated soils. Thus, there is a need to compare the relation between Cd fractions and soil characteristics in both contaminated and uncontaminated soil. Furthermore, any changes in the proportion of ex-Cd lead to changes in the proportions of inorganically bound, organically bound, and oxide-occluded $\mathrm{Cd}$. However, few articles have compared the relationships between $\mathrm{Cd}$ fractions in soil and soil properties in uncontaminated and contaminated soils of similar character. Therefore, to support the assessment of potential Cd risk in arable soils, it is important to determine the proportions of each soil $\mathrm{Cd}$ fraction by sequential extraction of soils.

The aim of this study was to evaluate the relationships between $\mathrm{Cd}$ fractions and soil properties in uncontaminated and contaminated soils.

\section{Materials and Methods}

2.1. Soils. Samples of Cd-contaminated soil were collected from 10 paddy fields in Hokuriku district that were contaminated with $\mathrm{Cd}$ by mining waste water and sediments deposited by flooding from the 1930s to 1960s [15]. It is probable that fields in this area produce rice grains with $\mathrm{Cd}$ concentrations above $0.4 \mathrm{mg} \mathrm{Cd} \mathrm{kg}^{-1}$, the new international threshold established by the Codex Alimentarius Commission [16] for Cd concentrations in brown rice. Uncontaminated soil samples were collected from 10 other paddy fields. All soils were collected from the plow layer from five points in each field and were bulked before analysis.

2.2. Analysis of Soil Physicochemical Properties. All samples were air-dried and passed through a 2-mm-mesh sieve before analysis. Soil $\mathrm{pH}$ was determined using a glass electrode (TOA $\mathrm{pH}$ meter HM-30S, Japan) with a $1: 2.5 \mathrm{w} / \mathrm{w}$ ratio of soil to either water or $1 \mathrm{~mol} \mathrm{~L}^{-1} \mathrm{KCl}$. The total carbon and total nitrogen concentrations were measured using an elemental analyzer (Perkin Elmer 2400 II, USA). There is no replication of the soil chemical analysis and the sequential extraction, because we applied the regression analysis for the data analysis.

2.3. Sequential Extraction of Soil $C d$. We extracted the soil $\mathrm{Cd}$ by means of a single-extraction method with $0.1 \mathrm{~mol} \mathrm{~L}^{-1}$ $\mathrm{HCl}$ solution $(1: 5 \mathrm{w} / \mathrm{v})$ by shaking side-to-side for $1 \mathrm{~h}$ [17]. The sequential extraction of Cd from soil was performed as follows (modified from [18]) using $3 \mathrm{~g}$ of dry soil and $30 \mathrm{~mL}$ of extraction solution. First, the ex-Cd fraction was obtained by extraction with $0.05 \mathrm{~mol} \mathrm{~L}^{-1} \mathrm{Ca}\left(\mathrm{NO}_{3}\right)_{2}(1: 10 \mathrm{w} / \mathrm{v}, 24 \mathrm{~h}$ shaking), and the extract was separated by centrifugation. Next, to obtain the inorganically bound Cd (in-Cd), the residue of the ex-Cd fraction was reextracted with $2.5 \%$ acetic acid $(1: 10 \mathrm{w} / \mathrm{v}, 24 \mathrm{~h}$ shaking). The organically bound Cd (or-Cd) was obtained by extraction with $2.5 \%$ acetic acid $(1: 10 \mathrm{w} / \mathrm{v}, 24 \mathrm{~h}$ shaking) after the decomposition of organic matter from the residue of the in-Cd fraction with $6 \% \mathrm{H}_{2} \mathrm{O}_{2}$. Finally, the oxide-occluded Cd (oc-Cd) was extracted from the residue of the or-Cd fraction with a mixture of $0.1 \mathrm{~mol} \mathrm{~L}^{-1}$ oxalate and $0.175 \mathrm{~mol} \mathrm{~L}^{-1}$ ammonium oxalate $(1: 30 \mathrm{w} / \mathrm{v})$ in a boiling water bath for $1 \mathrm{~h}$ with occasional stirring. Total soil $\mathrm{Cd}$ was quantified by digestion with concentrated $\mathrm{HNO}_{3}$ and $60 \% \mathrm{HClO}_{4}$. The difference between total $\mathrm{Cd}$ and the summed extracted fractions gave the residual fraction (re$\mathrm{Cd}$ ). The particle size distribution was determined using the pipette method [19]. The cation exchange capacity (CEC) and exchangeable cations were analyzed after extraction with $1 \mathrm{~mol} \mathrm{~L}^{-1} \mathrm{CH}_{3} \mathrm{COOHNH}_{4}$ (pH 7.0) [20]. Other analyses were performed based on the methods described by [21].

2.4. Statistical Analysis. The relationship between soil Cd fraction and soil properties was investigated using Pearson's correlation coefficient test at $P=0.05,0.01$, and 0.001 in Statcel 2 software [22]. Soil properties identified as statistically significant at $P<0.001$ in contaminated soil were compared with those in uncontaminated soil.

\section{Results}

3.1. Soil Properties. The chemical property values for the uncontaminated and contaminated soils were mentioned in Table 1 . The soil textures ranged from sandy loam to light clay. None of the soil chemical and physical properties differed significantly between uncontaminated and contaminated soils $(P>0.05)$.

\subsection{Chemical Forms of $C d$ in Uncontaminated and Contam-} inated Soils. Table 2 shows the concentration of each form of $\mathrm{Cd}$ and its proportion of the total. The average total $\mathrm{Cd}$ concentration was $0.26 \mathrm{mg} \mathrm{kg}^{-1}$ with a range from 0.21 to $0.36 \mathrm{mg} \mathrm{kg}^{-1}$ in uncontaminated soils. In contaminated soils, the average $\mathrm{Cd}$ concentration was $0.65 \mathrm{mg} \mathrm{kg}^{-1}$ ranging from 0.43 to $0.88 \mathrm{mg} \mathrm{kg}^{-1}$. The average concentration of each form of $\mathrm{Cd}\left(\mathrm{mg} \mathrm{kg}^{-1}\right)$ in uncontaminated and contaminated soils was exchangeable $(0.07,0.16)$; inorganically bound $(0.07$, $0.17)$; organically bound $(0.08,0.19)$; oxide occluded $(0.03$, $0.11)$; and residue $(0.02,0.03)$. The concentration of each form 


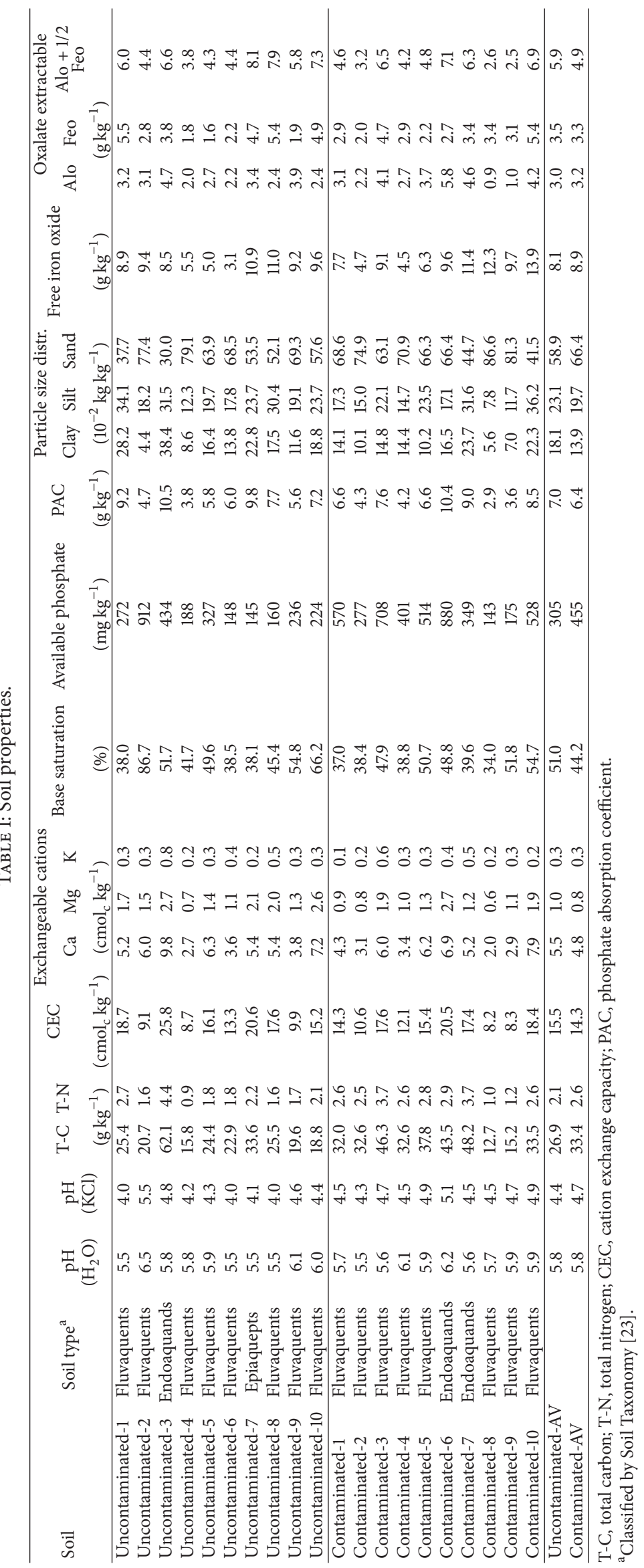




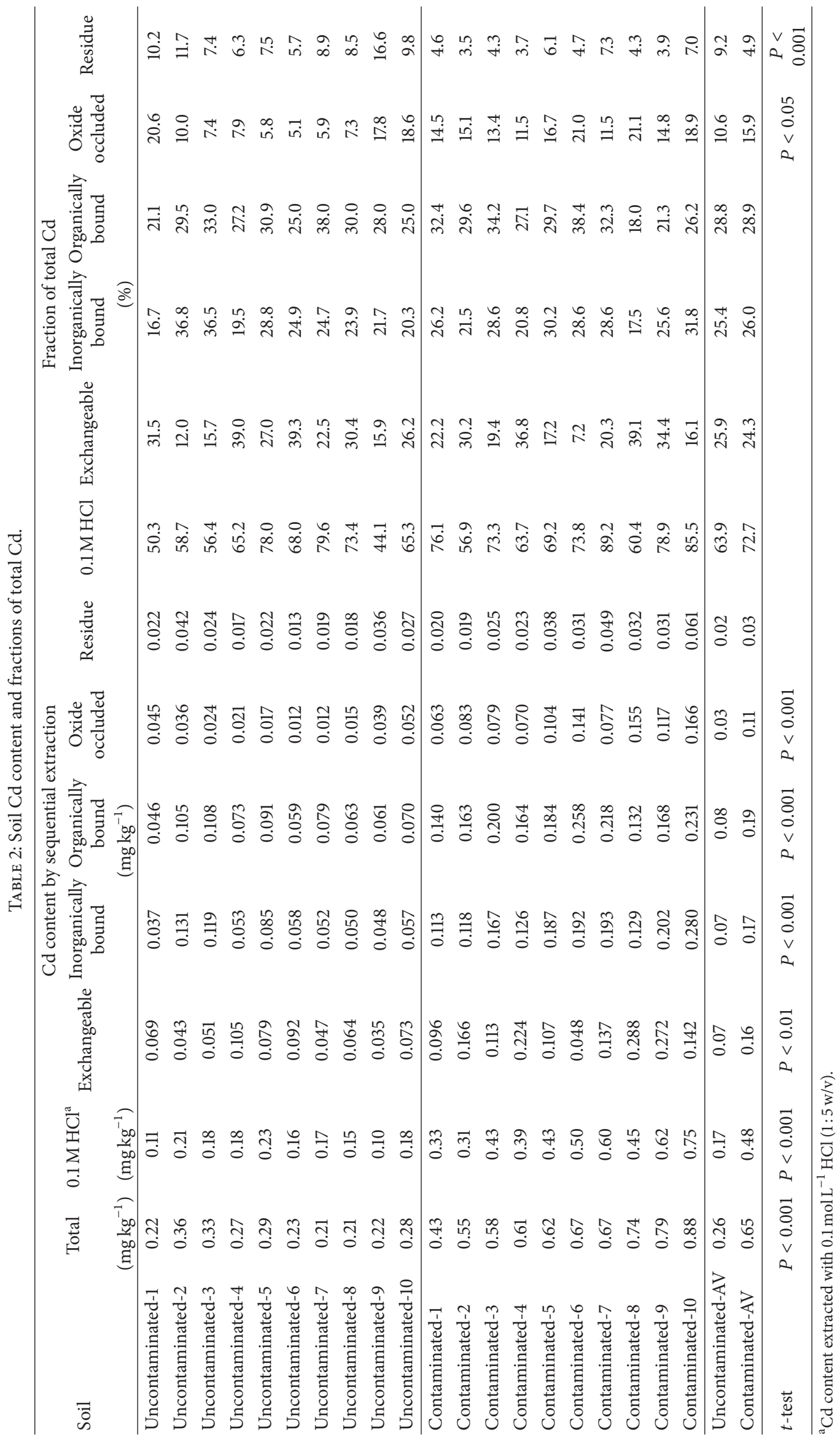


TABLE 3: Correlation between proportions of Cd chemical forms and soil properties ${ }^{\mathrm{a}}$.

\begin{tabular}{|c|c|c|c|c|c|c|c|c|c|c|}
\hline \multirow{2}{*}{$\begin{array}{l}\text { Soil } \\
\text { properties }\end{array}$} & \multicolumn{5}{|c|}{ Uncontaminated soils } & \multicolumn{5}{|c|}{ Contaminated soils } \\
\hline & Exchangeable & $\begin{array}{c}\text { Inorganically } \\
\text { bound }\end{array}$ & $\begin{array}{c}\text { Organically } \\
\text { bound }\end{array}$ & $\begin{array}{c}\text { Oxide } \\
\text { occluded }\end{array}$ & Residue & Exchangeable & $\begin{array}{c}\text { Inorganically } \\
\text { bound }\end{array}$ & $\begin{array}{c}\text { Organically } \\
\text { bound }\end{array}$ & $\begin{array}{c}\text { Oxide } \\
\text { occluded }\end{array}$ & Residue \\
\hline $\mathrm{pH}\left(\mathrm{H}_{2} \mathrm{O}\right)$ & $(-)^{*}$ & & & & & & & & & \\
\hline $\mathrm{pH}(\mathrm{KCl})$ & $(-)^{* *}$ & $(+)^{*}$ & & & & $(-)^{*}$ & $(+)^{*}$ & & & \\
\hline $\mathrm{T}-\mathrm{C}$ & & & & & & $(-)^{*}$ & & $(+)^{* * *}$ & & \\
\hline $\mathrm{T}-\mathrm{N}$ & & & & & & $(-)^{*}$ & & $(+)^{* *}$ & & \\
\hline CEC & & & & & & $(-)^{* * *}$ & $(+)^{* *}$ & $(+)^{* *}$ & & \\
\hline $\mathrm{Ex}-\mathrm{Ca}$ & & & & & & $(-)^{* * *}$ & $(+)^{* * * *}$ & & & $(+)^{*}$ \\
\hline Ex-Mg & & & & & & $(-)^{* *}$ & $(+)^{*}$ & & & \\
\hline \multicolumn{11}{|l|}{$\mathrm{Ex}-\mathrm{K}$} \\
\hline $\begin{array}{l}\text { Base } \\
\text { saturation }\end{array}$ & $(-)^{*}$ & & & & & & $(+)^{* *}$ & & & \\
\hline $\begin{array}{l}\text { Available } \\
\text { phosphate }\end{array}$ & $(-)^{*}$ & $(+)^{*}$ & & & & $(-)^{* *}$ & & $(+)^{* *}$ & & \\
\hline PAC & & & & & & $(-)^{* * *}$ & $(+)^{* *}$ & $(+)^{* *}$ & & \\
\hline \multicolumn{11}{|l|}{$\begin{array}{l}\text { Free iron } \\
\text { oxide }\end{array}$} \\
\hline Sand & & & & & & $(+)^{*}$ & $(-)^{*}$ & & & $(-)^{* *}$ \\
\hline Silt & & & & & & & $(+)^{* *}$ & & & $(+)^{* * * *}$ \\
\hline Clay & & & & & & & & & & $(+)^{*}$ \\
\hline $\begin{array}{l}\text { Alo + 1/2 } \\
\mathrm{Feo}^{\mathrm{b}}\end{array}$ & & & & & & $(-)^{* * *}$ & $(+)^{* *}$ & $(+)^{*}$ & & \\
\hline
\end{tabular}

a $(+)$ : positive correlation, $(-)$ : negative correlation, ${ }^{*}(P<0.05),{ }^{* *}(P<0.01)$, and ${ }^{* * *}(P<0.001)$.

${ }^{\mathrm{b}}$ Extracted with acid oxalate.

of Cd (except re-Cd) was significantly higher in contaminated soils than in uncontaminated soils $(P<0.01)$. The proportions of ex-Cd, in-Cd, and or-Cd were not significantly different between the soil types, but those of ox-Cd $(P<$ $0.05)$ and re-Cd $(P<0.001)$ were different. The sum of the proportions of ex-Cd, in-Cd, and or-Cd ranged from $65 \%$ to $90 \%$ in both soils and did not differ significantly.

3.3. Proportions of Chemical Forms of $C d$ and Soil Properties. The proportions of most chemical forms of Cd exhibited correlations with several soil properties (Table 3). In uncontaminated soils, ex-Cd displayed negative correlations with $\mathrm{pH}$ $\left(\mathrm{H}_{2} \mathrm{O}\right), \mathrm{pH}(\mathrm{KCl})$, base saturation, and available phosphate $(P<0.05$ or 0.01$)$, and in-Cd was positively correlated with $\mathrm{pH}(\mathrm{KCl})$ and available phosphate $(P<0.05)$. No other soil properties displayed any correlation with any $\mathrm{Cd}$ fractions in uncontaminated soils.

In the contaminated soils, ex-Cd showed strong negative correlations with $\mathrm{CEC}$, ex-Ca, ex-Mg, available phosphate, $\mathrm{PAC}$, and amorphous iron and aluminum oxides $(P<0.001$ or $P<0.01$ ), and in-Cd showed strong positive correlations with CEC, ex-Ca, base saturation, PAC, silt content, and amorphous iron and aluminum oxides $(P<0.001$ or 0.01). Additionally, strong positive correlations were observed between or-Cd and total C, total N, CEC, available phosphate, and PAC $(P<0.001$ or 0.01$)$; and re-Cd was correlated negatively with sand content $(P<0.01)$ and positively with silt content $(P<0.001)$. The remaining properties $\mathrm{pH}\left(\mathrm{H}_{2} \mathrm{O}\right)$,
ex-K, and free iron oxide were not correlated with any $\mathrm{Cd}$ fractions in either type of soil. Also, there are no correlations between ox-Cd and soil properties.

The soil properties that exhibited strong correlations with the proportions of $\mathrm{Cd}$ fractions in contaminated soils are shown in Figure 1. It is suggested that several of the soil properties in Figure 1 affect the proportions of $\mathrm{Cd}$ chemical forms and specifically the transformation of ex-Cd into inCd or or-Cd.

\section{Discussion}

4.1. Comparison of the Relationships between Soil Properties and Proportion of Exchangeable Cd between Uncontaminated and Contaminated Soils. Few articles have compared the relationships between $\mathrm{Cd}$ fractions and soil properties in uncontaminated and contaminated soils in detail. Sadamoto et al. [18] reported that the proportion of ex-Cd was approximately $20 \%$ in uncontaminated soil but approximately 30 to $40 \%$ in contaminated soil. However, we found no statistical difference in this proportion between uncontaminated and contaminated soils. Sadamoto et al. [18] used only three fluvic paddy soils (two contaminated, one uncontaminated), which did not represent a wide variety of properties such as particle size and total $\mathrm{C}$ content. Moreover, their contaminated soils contained large amounts of copper $(\mathrm{Cu})$ and a higher organic fraction than ours. The solubility constants of chelates formed between $\mathrm{Cd}$ and soil humic acid at $\mathrm{pH} 5$ and 7 are lower 

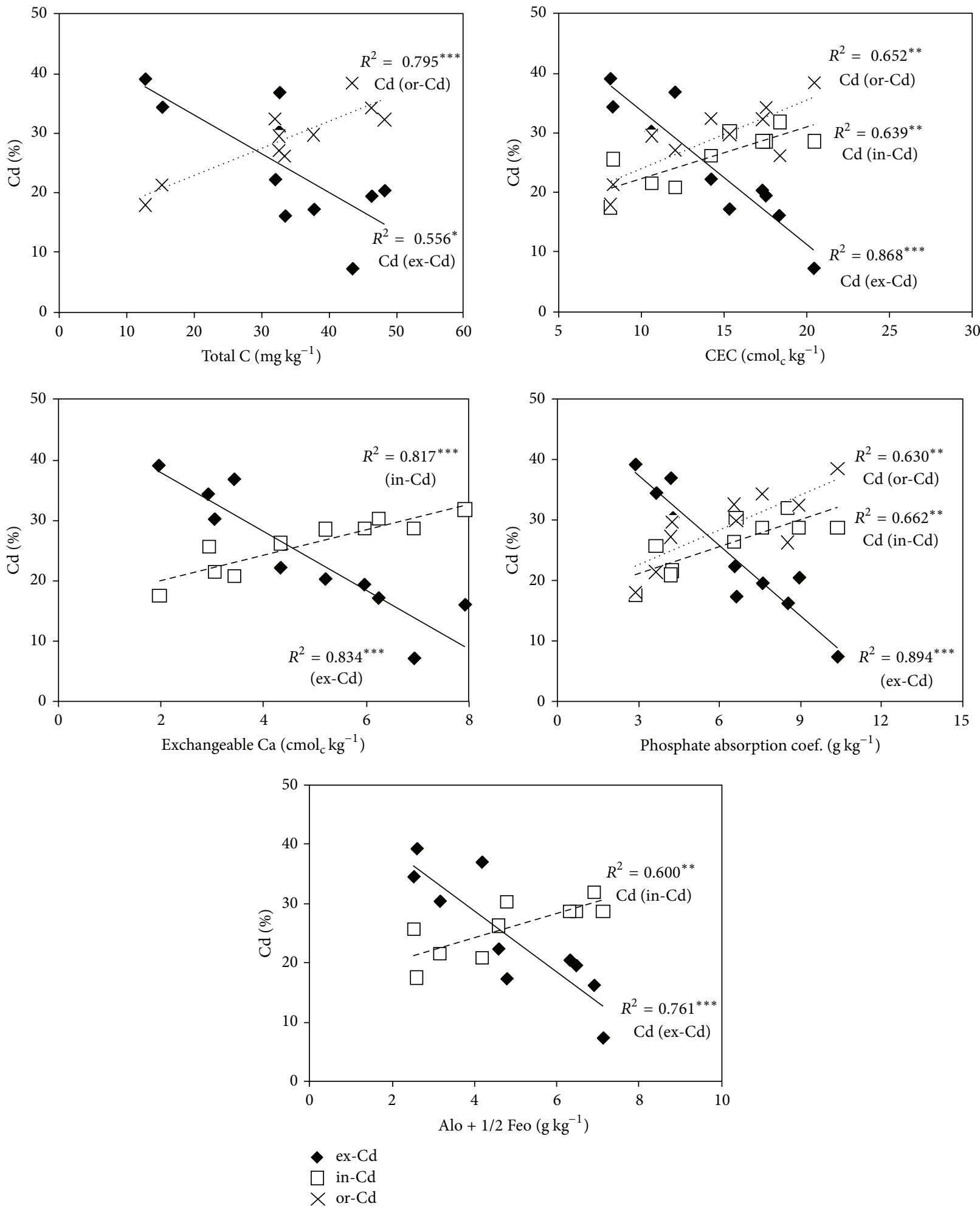

FIGURE 1: Correlation between proportions of Cd chemical forms and soil properties in contaminated soil.

than those of $\mathrm{Cu}[24]$, so we consider that the $\mathrm{Cd}$ was distributed primarily in the exchangeable fraction due to its lower covalent bonding to humic acid compared to $\mathrm{Cu}$. Morera et al. [25] studied the competitive adsorption of heavy metals in different soils and reported that Cd was scarcely adsorbed in the presence of $\mathrm{Cu}$. These results may identify the reason why the proportion of ex-Cd in the contaminated soil was not higher than that in the uncontaminated soil. 

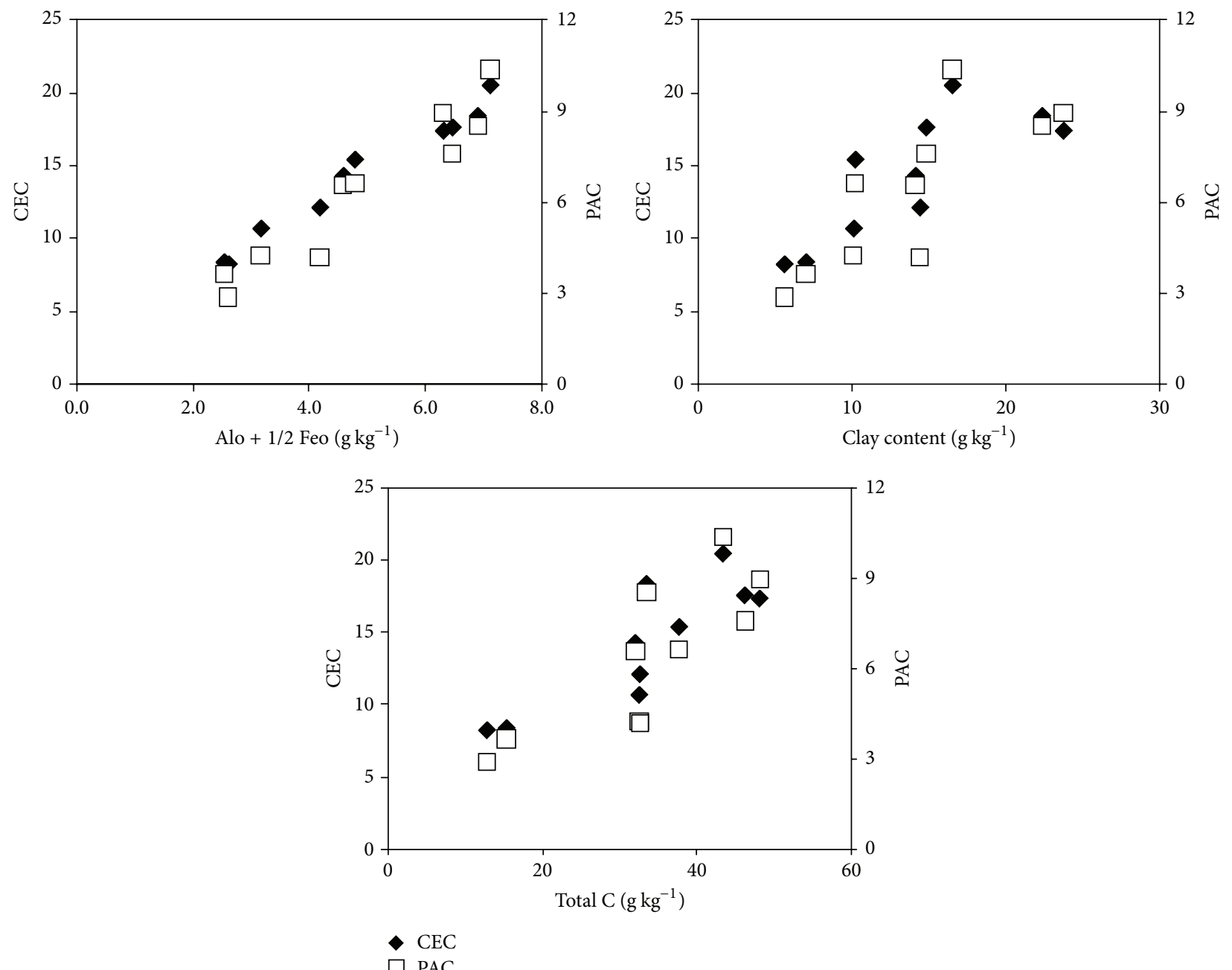

FIGURE 2: Relationships between cation exchange capacity (CEC), phosphate absorption coefficient (PAC), and relevant soil properties.

We suggest that the proportion of ex-Cd depends on the soil type and especially on differences in humic acid and $\mathrm{Cu}$ contents.

As the proportion of ex-Cd increased, the proportions of in-Cd and or-Cd decreased in both contaminated and uncontaminated soils (Table 2). Furthermore, there was no correlation between in-Cd and or-Cd. These fractions exist in equilibrium [26], so we consider that changes in soil moisture, soil $\mathrm{pH}$, oxidation-reduction state, and/or the decomposition of organic matter led to changes in the chemical forms of Cd in soil. During the extraction process by using a mixture of oxalate and ascorbic acid, ferrous oxalate dehydrate could be precipitate, which induced coprecipitation of some metals except $\mathrm{As}$ and $\mathrm{Cu}$ in Andisols [27]. This provides question validity of the extraction method, while it was used even recently. In our experiment, the existence ratios of ox-Cd and re-Cd are relatively low compared to other fractions, suggesting minor role of those fractions to plant availability and dynamics in soils. The effect of changes in soil conditions on the forms of $\mathrm{Cd}$ should be analyzed further.
4.2. Relationship between Cd Chemical Forms and Soil Properties. Heavy metals in soils are adsorbed to clay minerals, free oxides, and humic substances. Many methods have been used to fractionate these heavy metals [28-30]. As the proportion of ex-Cd in contaminated soils was not significantly higher than that in uncontaminated soils, we examined the relationships between the proportion of ex$\mathrm{Cd}$ and soil properties in contaminated soil in detail. In general, soil $\mathrm{pH}$ plays a major role in the adsorption of heavy metals: with decreasing soil $\mathrm{pH}$, the proportion of ex-Cd increases [31] and the proportion of in-Cd decreases [32]. As the $\mathrm{pH}$ of our contaminated soils ranged from 5.5 to 6.2 and there was no correlation between soil $\mathrm{pH}$ and any of the $\mathrm{Cd}$ fractions under the experimental conditions, the soil $\mathrm{pH}$ had no effect on the soil Cd fractions in these soils. Humic substances have many surface functional groups and can bind specific heavy metals. The total C content, which indicates the humic substance content, was strongly correlated with the proportion of or-Cd in the contaminated soils. However, it was only slightly correlated with ex-Cd and 
was not correlated with in-Cd. Therefore, the total C content primarily affected the or-Cd fraction. CEC and PAC were very strongly negatively correlated with ex-Cd and strongly positively correlated with in-Cd. We therefore investigated the relationships between the contents of total $\mathrm{C}$, clay, and amorphous iron and aluminum oxides, which are considered to affect CEC and PAC $[33,34]$ (Figure 2). The total C and clay contents were strongly correlated, and the amorphous iron and aluminum oxides correlated very strongly with CEC and PAC. Thus, the main Cd adsorbents in our soil samples were amorphous iron and aluminum oxides.

The binding of metals to inorganic soil constituents involves a continuum of reactive sites, ranging from those where there are weak physical forces (van der Waals forces) and electrostatic outer-sphere complexes (e.g., ion exchange) to those where precipitation [35] or strong chemical bonds occur (by inner-sphere complexation). The outer-sphere complex is formed on a negative electron charge resulting from isomorphous substitution. Because this complex can release metals easily with changes in the soil solution, its contents are available to plants. In contrast, the inner-sphere complex forms on clay edges or on the surfaces of metal hydroxides, the active surface hydroxide groups of which are able to bind to metals via coordinate bonds [36]. Because these bonds are stronger than the outer-sphere ones, the plant availability of those adsorbed metals is relatively lower. We consider that the reduction in the proportion of exCd with increasing CEC and PAC (Figure 1) was due to the formation of inner-sphere complexes with amorphous iron and aluminum oxides.

Yanagisawa et al. [2] suggested that the influence of soil texture, soil permeability, CEC, soil moisture, and other factors masks the correlation between soil properties and $\mathrm{Cd}$ content in brown rice. Because soil properties were correlated with the proportions of various $\mathrm{Cd}$ forms in our contaminated soils, we suggest that the soil properties determined the distribution of $\mathrm{Cd}$ forms derived from the same source.

Cd uptake by cabbage [10] and paddy rice [37] is affected by the fractions of $\mathrm{Cd}$ in the soil. Furthermore, the $\mathrm{Cd}$ content of soybean is affected by soil $\mathrm{pH}$, soil Cd content as extracted by $0.1 \mathrm{M} \mathrm{HCl}$, and PAC [38]. Thus, soil properties are very important for Cd uptake and are major factors to consider in estimating potential Cd risk in soils.

\section{Conclusion}

The sequential extraction of cadmium from soil revealed the relationship between chemical forms of soil $\mathrm{Cd}$ and properties in contaminated and uncontaminated paddy soils. The proportions of soil Cd fractions were almost the same between the two soil groups, although the Cd concentration of several fractions in contaminated soils was statistically higher than those in uncontaminated soils except for residual fraction. The proportion of exchangeable $\mathrm{Cd}$ was correlated with the CEC and PAC in contaminated soil but not in uncontaminated soil, suggesting a new finding on the difference of Cd-chemical form between the two soil groups. Soil properties appear to affect the proportions of soil Cd fractions in contaminated soil and should be considered when evaluating soil Cd mobility.

\section{Conflict of Interests}

The authors declare that there is no conflict of interests.

\section{References}

[1] Japanese Ministry of Health, Labour, and Welfare, Notification No. 183 of the Ministry of Health, Labour and Welfare, Japanese Ministry of Health, Labour and Welfare, 2010 (Japanese).

[2] M. Yanagisawa, Y. Shinmura, N. Yamada, A. Segawa, and K. Kid, "Heavy metal pollution and methods of restoration of polluted soils in the Jinzu River basin," Bulletin of the Toyama Agricultural Experiment Station, vol. 15, pp. 1-110, 1984 (Japanese).

[3] H. Watanabe and T. Koyama, "Soil testing in available microelements," Japanese Journal of Soil Science and Plant Nutrition, vol. 59, pp. 226-236, 1988 (Japanese).

[4] T. Kuboi, A. Noguchi, and J. Yazaki, "Evaluation of ammonium nitrate extraction method for predicting plant-available cadmium," Japanese Journal of Soil Science and Plant Nutrition, vol. 60, pp. 22-28, 1989 (Japanese).

[5] T. Ibaraki, K. Kadoshige, and M. Murakami, "Evaluation of extraction methods for plant-available soil cadmium to wheat by several extraction methods in cadmium-polluted paddy field," Soil Science \& Plant Nutrition, vol. 51, no. 6, pp. 893-898, 2005.

[6] M. Chino, "The distribution of heavy metals in rice plants as influenced by the time and path of supply," Japanese Journal of Soil Science and Plant Nutrition, vol. 44, pp. 204-210, 1973 (Japanese).

[7] M. Masui, N. Kanemaru, H. Takesako, H. Miyakoda, I. Nanba, and H. Takahashi, "Annual surveys on correlation between the degree of cadmium contamination of paddy field rice grain and the number of dry paddy-field days in the cadmium contaminated area in Tama region of Tokyo," Bulletin of the Tokyo Agricultural Experiment Station, vol. 5, pp. 1-5, 1971 (Japanese).

[8] T. Asami, M. Kubota, and K. Orikasa, "Fractionation of soil cadmium and absorption by rice," in Proceedings of the 1st Symposium on Republic Pollution of Soil and Underground, pp. 109-118, 1986 (Japanese).

[9] H. Hattori, E. Asari, and M. Chino, "Estimate of cadmium concentration in brown rice," in Proceedings of the 17th World Congress of Soil Science, Paper No. 1992, pp. 1-5, Bangkok, Thailand, August 2002.

[10] X. Xian, "Effect of chemical forms of cadmium, zinc, and lead in polluted soils on their uptake by cabbage plants," Plant and Soil, vol. 113, no. 2, pp. 257-264, 1989.

[11] C. Konno, "Effect of oxidation-reduction on exchangeable Cd of Cd polluted soils," Tohoku Journal of Agricultural Research, vol. 53, pp. 61-62, 2000 (Japanese).

[12] M. A. Kashem and B. R. Singh, "Transformations in solid phase species of metals as affected by flooding and organic matter," Communications in Soil Science and Plant Analysis, vol. 35, no. 9-10, pp. 1435-1456, 2004.

[13] C. W. Gray, R. G. McLaren, A. H. C. Roberts, and L. M. Condron, "Solubility, sorption and desorption of native and added cadmium in relation to properties of soils in New 
Zealand," European Journal of Soil Science, vol. 50, no. 1, pp. 127$137,1999$.

[14] Q. B. He and B. R. Singh, "Effect of organic matter on the distribution, extractability and uptake of cadmium in soils," Journal of Soil Science, vol. 44, no. 4, pp. 641-650, 1993.

[15] H. Ito and K. Iimura, "Investigation on natural abundance and pollution by heavy metals of rivers, soils and crops in Hokuriku district: study on heavy metal pollution of soils (part 3)," Bulletin of the Hokuriku National Agricultural Experiment Station, vol. 22, pp. 101-162, 1979 (Japanese).

[16] Codex Alimentarius Commission, "Report of the twenty-eighth session," Alinorm 05/28/12, Codex Alimentarius Commission, 2005.

[17] D. E. Baker and M. C. Amacher, "Nickel, copper, zinc, and cadmium," in Methods of Soil Analysis. Part 2, A. L. Page, R. H. Miller, and D. R. Keeney, Eds., Agronomy Monograph no. 9, pp. 323-336, ASA and SSSA, Madison, Wis, USA, 2nd edition, 1982.

[18] H. Sadamoto, K. Iimura, T. Honna, and S. Yamamoto, "Extraction of fractionation of heavy metals in soils," Japanese Journal of Soil Science and Plant Nutrition, vol. 65, pp. 645-653, 1994 (Japanese).

[19] P. R. Day, "Particle fractionation and particle-size analysis," in Methods of Soil Analysis, Part 1, C. A. Black, D. D. Evans, J. L. White, L. E. Ensminger, and F. E. Clark, Eds., pp. 545-567, American Society of Agronomy, Madison, Wis, USA, 1965.

[20] J. Muramoto, I. Goto, and M. Ninaki, "Rapid analysis of exchangeable cations and cation exchange capacity (CEC) of soils by a shaking extraction method," Japanese Journal of Soil Science and Plant Nutrition, vol. 63, pp. 210-215, 1992 (Japanese).

[21] Dojo youbun bunseki hou iinkai, "Dojo youbun bunseki hou," edited by H. Imai, Yokendo Ltd., Tokyo, 1970 (Japanese).

[22] H. Masui, 4 Steps Excel Toukei. Statcel 2, OMS Publication, Saitama, Japan, 2nd edition, 2007 (Japanese).

[23] Soil Survey Staff, Keys to Soil Taxonomy, USDA, Natural Resources Conservation Service, Washington, DC, USA, 8th edition, 1998.

[24] H. Takenaga and S. Aso, "Studies on the physiological effect of humic acid (part 9): stability constants of cation-nitrohumic acid chelates," Japanese Journal of Soil Science and Plant Nutrition, vol. 46, pp. 349-354, 1975 (Japanese).

[25] M. T. Morera, J. C. Echeverría, C. Mazkiarán, and J. J. Garrido, "Isotherms and sequential extraction procedures for evaluating sorption and distribution of heavy metals in soils," Environmental Pollution, vol. 113, no. 2, pp. 135-144, 2001.

[26] K. Iimura and H. Ito, "Behavior and balance of contaminant heavy metals in paddy soils: studies of heavy metal pollution of soils (part 2)," Research Bulletin of the Hokuriku National Agricultural Experiment Station, vol. 21, pp. 95-145, 1978 (Japanese).

[27] A. Suda and T. Makino, "Methodological drawbacks of the extraction of trace metals from $\mathrm{Fe}$ and Mn oxides in soil samples with oxalic acid-ammonium oxalate-ascorbic acid solution," Water, Air, \& Soil Pollution, vol. 226, article 12, 10 pages, 2015.

[28] R. G. McLaren and D. V. Crawford, "Studies on soil copper I. The fractionation of copper in soils," Journal of Soil Science, vol. 24, no. 2, pp. 172-181, 1973.

[29] A. Tessier, P. G. C. Campbell, and M. Blsson, "Sequential extraction procedure for the speciation of particulate trace metals," Analytical Chemistry, vol. 51, no. 7, pp. 844-851, 1979.

[30] L. M. Shuman, "Fractionation method for soil microelements," Soil Science, vol. 140, no. 1, pp. 11-22, 1985.
[31] X. Xian and G. Shokohifard, "Effect of pH on chemical forms and plant availability of cadmium, zinc, and lead in polluted soils," Water, Air, and Soil Pollution, vol. 45, no. 3-4, pp. 265273, 1989.

[32] Y. Kang, T. Miura, and T. Kosaki, "Influence of pH change on Cd leachability and chemical forms of contaminated soil," Pedologist, vol. 42, pp. 57-61, 1998.

[33] M. Nanzyo, K. Tsuruno, and Y. Watanabe, "Method for evaluating phosphate retention capacity of soils at constant final phospate concentration," Japanese Journal of Soil Science and Plant Nutrition, vol. 55, pp. 325-331, 1984 (Japanese).

[34] S. Shoji, T. Ito, M. Saigusa, and I. Yamada, "Properties of nonallophanic Andosols from Japan," Soil Science, vol. 140, no. 4, pp. 264-277, 1985.

[35] G. Sposito, The Chemistry of Soils, Oxford University Press, New York, NY, USA, 1989.

[36] D. L. Sparks, "Toxic metals in the environment: the role of surfaces," Elements, vol. 1, no. 4, pp. 193-197, 2005.

[37] M. Murakami and N. Ae, "Comparison of cadmium uptake ability of rice and maize from Cd-contaminated paddy fields," in Proceedings of the 1st International Symposium on Japan-Korea Research Cooperation, Abstract, pp. 70-71, National Institute of Agro-Environmental Sciences, Tsukuba, Japan, 2003.

[38] K. Sugahara, T. Makino, and Y. Sakurai, "Development of a crop-soil database for evaluation of the risk of cadmium contamination in staple crops," in Materials Circulation through Agro-Ecosystems in East Asia and Assessment of Its Environmental Impact, Y. Hayashi, Ed., NIAES Series no. 5, pp. 129-135, National Institute of Agro-Environmental Sciences, Tsukuba, Japan, 2004. 

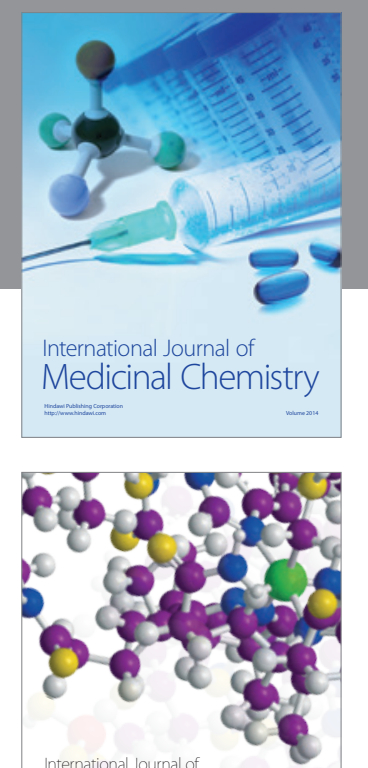

\section{Carbohydrate} Chemistry

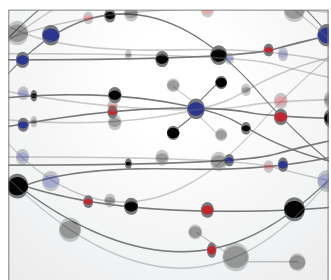

The Scientific World Journal
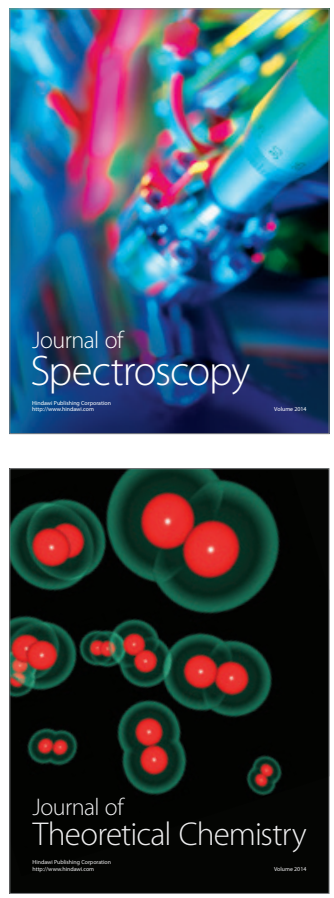
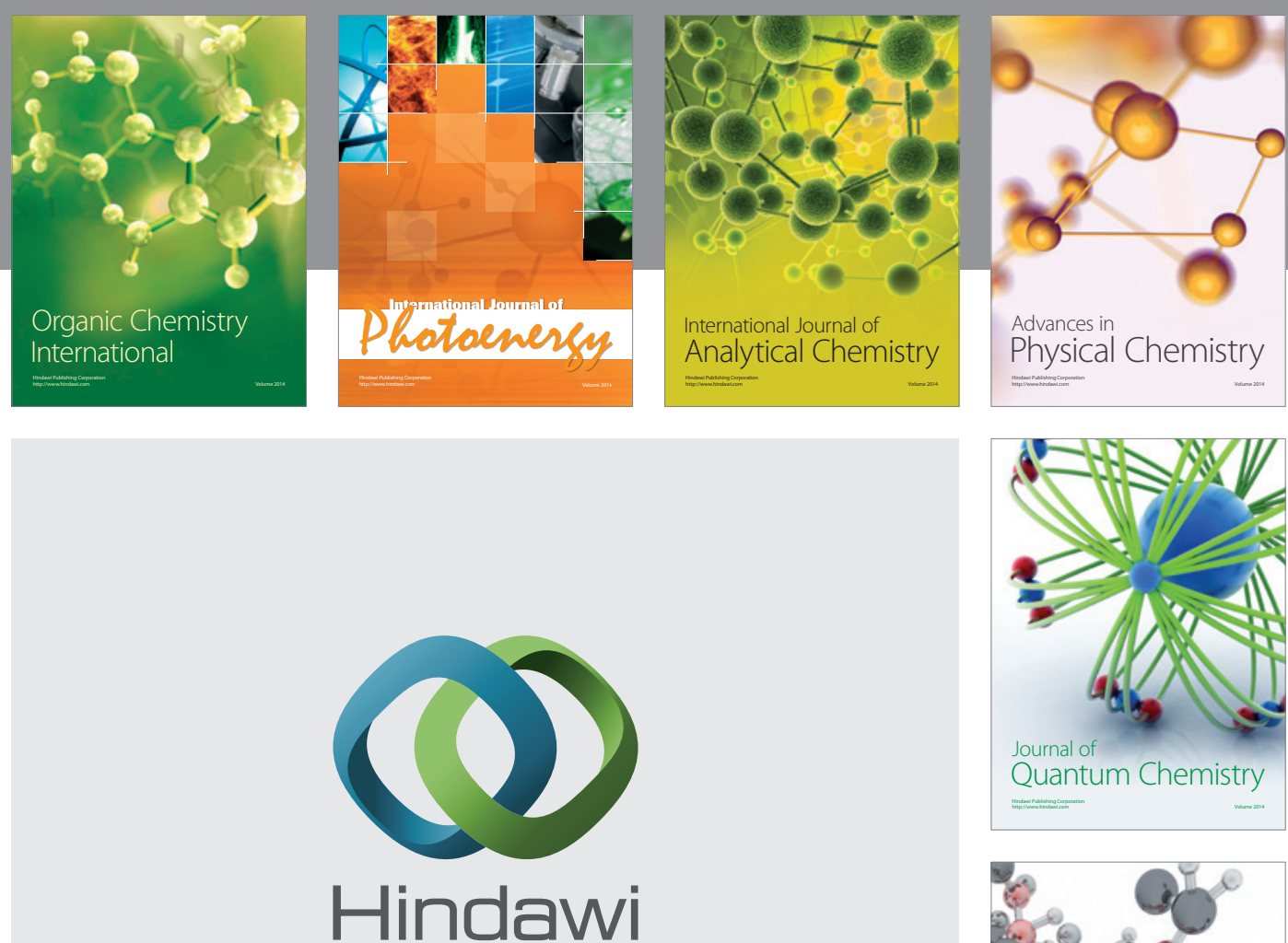

Submit your manuscripts at

http://www.hindawi.com

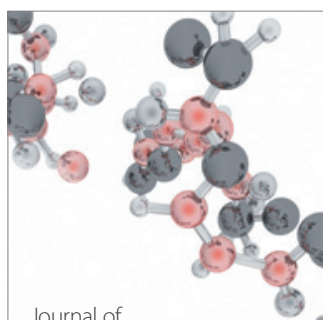

Analytical Methods

in Chemistry

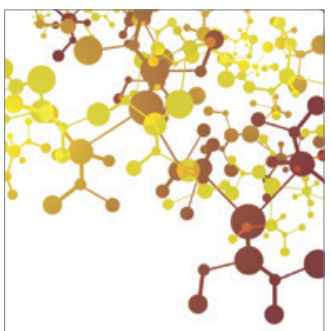

Journal of

Applied Chemistry

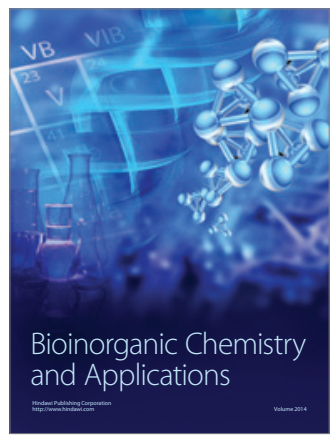

Inorganic Chemistry
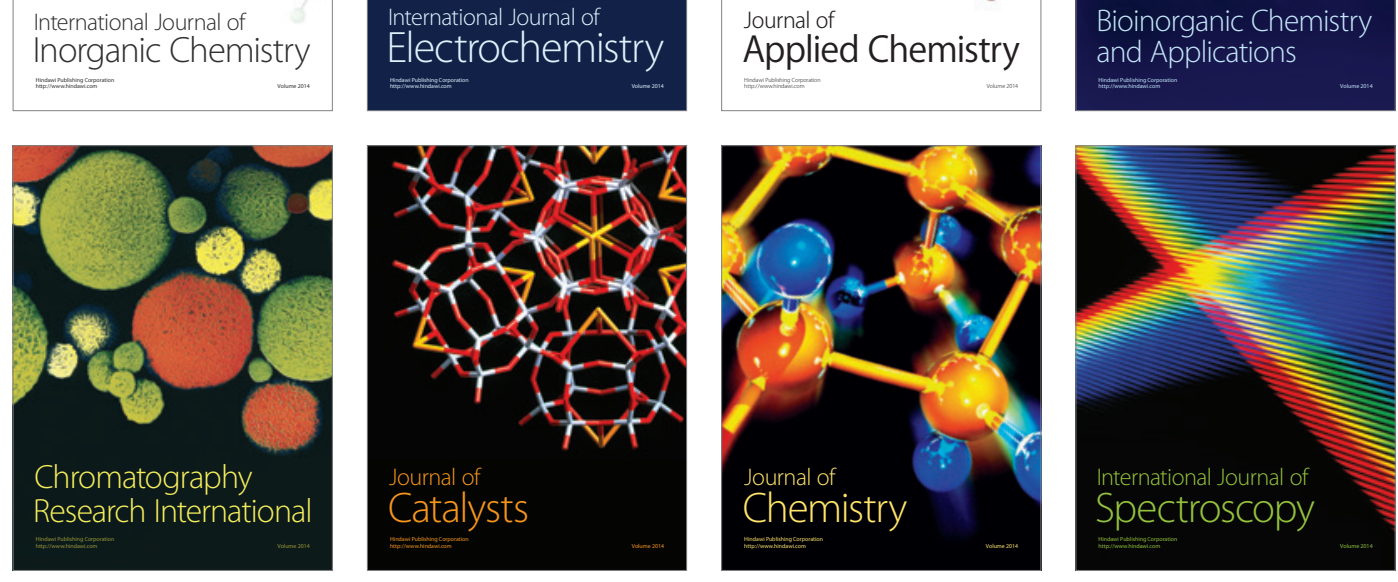